\title{
Algunas esculturas napolitanas en la diócesis de Tarazona (Zaragoza).
}

Some Neapolitan sculptures in the diocese of Tarazona (Zaragoza).

Rebeca CARRETERO CALVO

Universidad de Zaragoza

Resumen: En este artículo se reúne un conjunto de esculturas napolitanas localizadas en el antiguo territorio de la diócesis de Tarazona, más amplio que el actual, en parte ya conocidas, junto a otras inéditas. Igualmente, se intenta atribuir la factura de dichas tallas italianas a sus correspondientes escultores o, en su defecto, a su círculo artístico.

Palabras clave: Escultura napolitana, Siglo XVII, Siglo XVIII, Tarazona, Calatayud, Giacomo Colombo, Pietro Ceraso, Gaetano Patalano, Jacobo Bonavita.

RÉsumÉ: Dans cet article, on recueille certaines sculptures napolitaines déjà connues situées sur l'ancien territoire $\mathrm{du}$ diocèse de Tarassone, plus grand qu'actuellement, et on en fait connaître d'autres nouvelles. On essaye également d'attribuer l'exécution de ces oeuvres italiennes à leur sculpteurs respectifs ou, à défaut, à leur cercle artistique.

Mots clef: Sculpture napolitaine, XVII e siècle, XVIII e siècle, Tarassone, Calatayud, Giacomo Colombo, Pietro Ceraso, Gaetano Patalano, Jacobo Bonavita.

Hasta la restructuración geográfica llevada a cabo en 1956 en varias diócesis españolas, la de Tarazona englobaba parroquias de las provincias civiles de Zaragoza, Navarra, Soria y La Rioja, si bien ya para 1783 Tudela había conseguido desmembrarse del obispado turiasonense encabezando uno propio ${ }^{1}$. Este vasto territorio, rico en iglesias parroquiales y colegiales y en funda-

${ }^{1}$ M. TELLO ORTIZ, "Episcopologio de Tarazona", Aragonia Sacra, 16-17, 2001-2003, p. 192. ciones conventuales, alberga un extraordinario patrimonio histórico-artístico del que ahora sólo queremos destacar una pequeña parte: las esculturas de procedencia napolitana que llegaron a él entre los siglos XVII y XVIII.

Son varios los estudios que en los últimos años han incidido en el mecenazgo artístico de los virreyes de Nápoles, así como de eclesiásticos o comerciantes españoles, que durante los siglos del Barroco adquirie- 
ron masivamente obras partenopeas tanto para su disfrute personal como para ser donadas a distintos establecimientos religiosos de nuestro país ${ }^{2}$. En la mayoría de los casos se trata de esculturas lígneas policromadas de formato reducido pues ello facilitaba su transporte a España al tiempo que abarataba sus costes ${ }^{3}$.

Este interesante fenómeno artístico, que se ha rastreado en la práctica totalidad del territorio nacional, alcanzó también la diócesis de Tarazona. En este sentido, este trabajo pretende constituir una primera aproximación a la presencia de la escultura de procedencia napolitana en el antiguo territorio del obispado turiasonense, como se ha advertido más amplio que el actual, en el que reuniremos las obras ya conocidas y sacaremos a la luz otras nuevas. De igual modo, y ante la ausencia de documentación y bibliografía que por el momento ayude a revelar su autoría, intentaremos atribuir la factura de dichas tallas italianas a sus correspondientes escultores o, en su defecto, a su círculo artístico, apoyándonos en la comparación formal de dichas piezas con otras de autoría bien acreditada. Asimismo, llevaremos a cabo aportaciones tan valiosas como el hallazgo de la firma de Jacobo Bonavita en dos de los cuatro magníficos ejemplares napolitanos custodiados en la sacristía de la colegiata del Santo Sepulcro de Calatayud.

Con todo, vemos necesario insistir una vez más en que las esculturas napo-

\footnotetext{
${ }^{2}$ Sólo citaremos los estudios más recientes entre los que se encuentran I. MAURO, "Le acquisizioni di opere d'arte di Gaspar de Bracamonte y Guzmán, conte di Peñaranda e viceré di Napoli (1659-1664)", Locvs Amoenvs, 9, 2007-2008, pp. 155-169; D. CARRIÓ-INVERNIZZI, El gobierno de las imágenes. Ceremonial y mecenazgo en la Italia española de la segunda mitad del siglo XVII, Madrid, 2008; y J. L. COLOMER (dir.), España y Nápoles. Coleccionismo y mecenazgo virreinales en el siglo XVII, Madrid, 2009.

${ }^{3}$ R. ALONSO MORAL, "La Inmaculada de Giacomo Colombo. Una escultura en su contexto italiano", Bulletina Boletín Bulletin del Museo de Bellas Artes de Bilbao, 7, 2013, p. 176.
}

litanas localizadas en la diócesis del Moncayo adolecen en la mayor parte de las ocasiones de falta de datos que nos permitan desvelar, al menos hasta el momento, quién fue el personaje que encargó en tierras italianas la hechura de estas preciosas imágenes y cuáles fueron los detalles de su envío. No obstante, en la ciudad de Tarazona conocemos un caso en el que sucede justamente lo contrario pues, aunque la pieza en cuestión no ha llegado a nuestros días, tenemos constancia documental de la existencia de una talla napolitana en el colegio de San Vicente mártir de la Compañía de Jesús.

En efecto, gracias al documento de entrega que se custodia en el Archivo Histórico de Protocolos Notariales de Tarazona ${ }^{4}$, sabemos que el 22 de enero de 1654 el doctor Andrés González de Lluba, vicario de la iglesia de San Pablo de Zaragoza, hermano del jesuita Miguel González de Lluba, residente en el colegio turiasonense en ese momento y del que había sido rector, "movido de piedad y devocion", donaba a los jesuitas de Tarazona una escultura "preciosa y mui delicada" del Niño Jesús que había "hecho traer de Napoles". La dádiva iba condicionada por un único requisito, consistente en que en ningún momento y bajo ningún pretexto pudiera sacarse de la casa y que, de no cumplirse, supondría el traspaso de la talla al colegio de Huesca ${ }^{5}$. A la vista de esta aportación documental nos percatamos de que la llegada de esculturas procedentes de Nápoles a nuestro país podía provenir de la actuación de muy diversos miembros del estamento eclesiástico, además de la munificencia de virreyes, nobles y ricos comerciantes.

A partir de aquí realizaremos un recorrido por los distintos enclaves del terri-

\footnotetext{
${ }^{4}$ Archivo Histórico de Protocolos Notariales de Tarazona, Prudencio Ruiz de Pereda, 1654-1655, fols. 52 r.-52 v. (Tarazona, 22-I-1654).

${ }^{5}$ R. CARRETERO CALVO, Arte y arquitectura conventual en Tarazona en los siglos XVII y XVIII, Tarazona, 2012, p. 146.
} 
torio diocesano que albergan esculturas de procedencia napolitana, aunque con el convencimiento de que todavía quedan algunas piezas a la espera de ser catalogadas como tales. Al mismo tiempo, analizaremos brevemente cada ejemplar y, debido a la ausencia documental y bibliográfica ya declarada, intentaremos adjudicar su factura al artista partenopeo correspondiente o a su círculo a partir de su comparación formal con algunas de sus obras.

\section{ESCULTURAS NAPOLITANAS EN EL CONVENTO DE CONCEPCIONIS- TAS DESCALZAS DE ÁGREDA}

En la diócesis turiasonense los casos más paradigmáticos se centran en el convento de concepcionistas descalzas de Ágreda (Soria) y durante los últimos años de vida de sor María de Jesús (1602-1665). De hecho, Ana Fernández de Córdoba y Figueroa, segunda esposa de Pedro Antonio de Aragón, virrey de Nápoles (1665-1671) y Aragón, gentilhombre de Felipe IV y Carlos II y embajador en Roma, envió a la Venerable hacia 1665, poco antes de morir ésta, un Niño Jesús de Nápoles conocido como "de Gloria" 6 . Por su parte, la condesa del Fresno, mujer del conde de Peñaranda, asimismo virrey de Nápoles entre 1659 y 1664, remitió desde la ciudad italiana al cenobio agredeño una talla de Santa Teresa de Jesús ${ }^{7}$.

Aunque no en tiempos de sor María pero sí relacionada con ella se encuentra también la dádiva de Fadrique Álvarez de Toledo y Ponce de León (1635-1705), séptimo marqués de Villafranca y duque de Fernandina, virrey de Sicilia y Nápoles, consejero de Estado y hombre de peso en la corte de Carlos II, asiduo lector de la Mística Ciudad de Dios. En 1707 don Fadrique envió a Ágreda una escultura de San

${ }^{6}$ R. FERNÁNDEZ GRACIA, Arte, Devoción y Política. La promoción de las artes en torno a sor María de Ágreda, Soria, 2002, pp. 141-143, reproducido en p. 142.

\footnotetext{
${ }^{7}$ Ibídem, pp. 143-147, reproducida en p. 146.
}

Nicolás con una reliquia realizada en Nápoles por "el mejor artífice" 8 . Sin embargo, como ya advierte el profesor Fernández Gracia, la rigidez del santo de Bari no permite asegurar que la calidad del artista sea tan elevada?

Las donaciones más importantes fueron, no obstante, las que llevó a cabo el cardenal Pascual de Aragón, virrey de Nápoles entre 1664 y $1666^{10}$, metrópoli en la que en 1665 adquirió dos magníficas esculturas para el convento de Ágreda, aunque no llegarían a tierras sorianas hasta después de la muerte de la Venerable. La primera de ellas es una hermosa imagen de la Inmaculada Concepción de madera policromada con cabello postizo ${ }^{11}$ y la segunda representa a San

\footnotetext{
${ }^{8}$ Aunque ahora se conserva en el convento de concepcionistas de La Puebla de Montalbán (Toledo).

${ }^{9}$ R. FERNÁNDEZ GRACIA, Op. cit., pp. 152-155, reproducido en p. 153.

${ }^{10}$ El cardenal Aragón ejerció una intensa labor de mecenazgo en el convento de capuchinas de Toledo, donde descansan sus restos mortales, al que donó importantes piezas italianas, como se estudia en J. NICOLAU CASTRO, "La correspondencia del cardenal don Pascual de Aragón a las madres capuchinas", Toletum: boletín de la Real Academia de Bellas Artes y Ciencias Históricas de Toledo, 26, 1991, pp. 9-23; ÍDEM, “El Cardenal Virrey don Pascual de Aragón y su Monasterio toledano de Madres Capuchinas", en Ricerche sul 600'napoletano. Saggi e documenti, Nápoles, 1999, pp. 77-89; ÍDEM, “El exconvento de madres capuchinas, un museo de arte italiano en el corazón de Toledo", Toletum: boletín de la Real Academia de Bellas Artes y Ciencias Históricas de Toledo, 54, 2007, pp. 43-89; y M. HERMOSO CUESTA, "«Boccato di cardinale». Algo más sobre don Pascual de Aragón y el convento de capuchinas de Toledo", en F. J. CAMPOS Y FERNÁNDEZ DE SEVILLA (coord.), La clausura femenina en el Mundo Hispánico: una fidelidad secular, Actas del XIX Simposium, El Escorial, 2011, pp. 807-826.
}

${ }^{11}$ R. FERNÁNDEZ GRACIA, Op. cit., pp. 160-163, reproducida en $p$. 161. Resulta interesante destacar que la proclamación de la festividad de la Inmaculada Concepción como fiesta de precepto en el reino de Nápoles tuvo lugar en 1665 según mandato del virrey Pascual de Aragón. Sobre esta cuestión puede consultarse D. CARRIÓ-INVERNIZZI, "El poder de un testimonio visual. El retrato de Felipe IV y Pascual de Aragón de Pietro del Po (1662)", en J. L. PALOS I PEÑARROYA y D. CARRIÓ-INVERNIZZI (coords.), La historia imagi- 
José con el Niño. La Inmaculada ha sido atribuida por Margarita Estella a Pietro Cera$\mathrm{so}^{12}$. Asimismo, la Dra. Estella relaciona esta talla con otras piezas localizadas en la diócesis turiasonense -la Inmaculada Concepción del Santo Sepulcro de Calatayud (Zaragoza) y la del convento de Miedes de Aragón (Zaragoza), de las que trataremos en seguidaenglobándolas en una gran familia en la que también se encontraría la escultura de idéntica advocación del convento de carmelitas descalzas de Toledo, obra de Ceraso ${ }^{13}$ y la única creación firmada del grupo ${ }^{14}$.

La segunda escultura procedente de Nápoles y remitida después de 1665 al convento de Ágreda por el cardenal Pascual de Aragón representa a San José con el Niño de la mano. Nos encontramos ante un grupo de notable calidad en el que Jesús es el único que luce una larga cabellera morena postiza ${ }^{15}$. Este Infante resulta muy semejante al que conservan, en el interior de una vitrina, las concepcionistas de Miedes (Fig. 1), sobre el que volveremos más adelante.

nada: construcciones del pasado en la Época Moderna, Madrid, 2008, pp. 85-99; y R. ALONSO MORAL, Op. cit., pp. 187-188.

${ }^{12} \mathrm{M}$. ESTELLA MARCOS, "La corte virreinal y su influencia en las artes. El mecenazgo de los Toledo", en M. CABAÑAS, A. LÓPEZ-YARTO y W. RINCÓN (coords.), Arte, poder y sociedad en la España de los siglos XV a XX, Madrid, 2008, pp. 231-232; ÍDEM, “La escultura napolitana en España: comitentes, artistas y dispersión", en L. GAETA (ed.), La Scultura meridionale in Etá Moderna ne suoi rapporti con la circolazione mediterránea, Lecce, 2007, vol. II, p. 106.

${ }^{13}$ Isabella di Liddo mantiene que la Inmaculada toledana está firmada por Francesco Ceraso, en I. di LIDDO, La circulazione della scultura lignea barocca nel Mediterraneo. Napoli, la Puglia e la Spagna. Una indagine comparata sul ruolo delle botteghe: Nicola Salzillo, Roma, 2008, pp. 52-54.

${ }^{14}$ M. ESTELLA MARCOS, "La corte virreinal...", pp. 229-232.

${ }^{15}$ R. FERNÁNDEZ GRACIA, Op. cit., p. 164. Reproducida en dicha página.

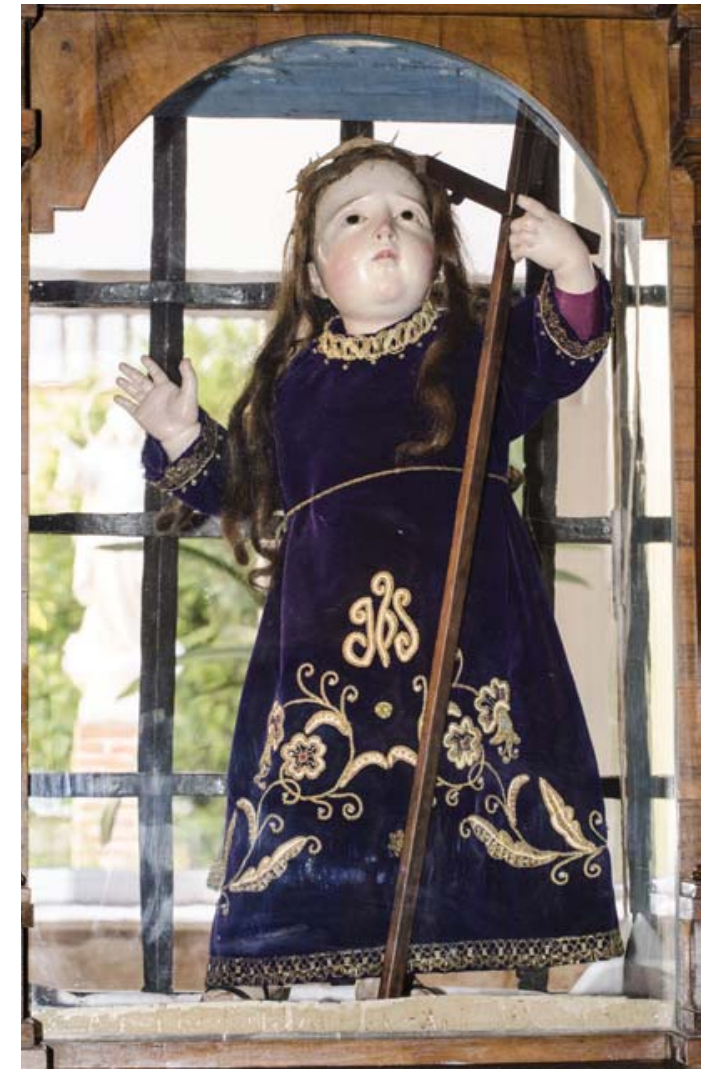

- Fig. 1. Niño Jesús Nazareno. Gaetano Patalano (atribuido). Convento de concepcionistas de Miedes. Foto Rafael Lapuente.

Margarita Estella sugirió la relación del grupo de Ágreda con la obra del escultor napolitano Gaetano Patalano (1655-después de 1700$)^{16}$. A este respecto, sólo podemos advertir que la producción artística documentada de Patalano está datada entre 1675 y $1700^{17}$ y que Pascual de Aragón desempeñó el cargo de virrey de Nápoles hasta 1666, por lo que la cronología no es compatible. Sin embargo, como también apuntara la Dra. Estella, lo cierto es que los artistas napolitanos muestran en general unos estilemas tan parecidos que, en ocasiones, resulta verdaderamente complicado cerrar de forma definitiva las atribuciones.

${ }^{16}$ M. ESTELLA MARCOS, “Caracteres del envío de esculturas lígneas napolitanas a España", en M. CABAÑAS, A. LÓPEZ-YARTO y W. RINCÓN (coords.), El arte y el viaje, Madrid, 2011, p. 569.

${ }^{17}$ I. di LIDDO, Op. cit., pp. 94-141, especialmente p.127. 
El convento agredeño todavía atesora dos magníficas tallas napolitanas más, enviadas a la clausura por Juana de la Cerda y Aragón, duquesa de Alburquerque, en 1693. La primera representa a San Miguel venciendo al demonio mientras que la segunda muestra a San Francisco de Asís meditando ante el Crucifijo $^{18}$. La extraordinaria escultura de San Miguel ha sido atribuida a Nicola Fumo (1645-1725) por Margarita Estella y relacionada con otros ejemplares localizados en nuestro país ${ }^{19}$. Por su parte, San Francisco de Asís meditando ante el Crucifijo parece cercano a la producción escultórica de Giacomo Colombo, artista que trabajó en numerosas ocasiones para comitentes españoles ${ }^{20}$.

\section{TALLAS DE PROCEDENCIA NAPO- LITANA EN LA CIUDAD DE CALA- TAYUD}

Son cuatro las esculturas napolitanas custodiadas en la capilla de San Blas de la colegiata del Santo Sepulcro de Calatayud que representan a la Inmaculada Concepción (Fig. 2), San José con el Niño, San Miguel venciendo al mal y San Jorge y el dragón. Siguiendo un documento de 1845 que probablemente sea el escrito por Mariano del Cos y Felipe Eya-

${ }_{18}$ Ambas obras fueron dadas a conocer asimismo por el profesor Fernández Gracia, aunque las atribuyó a Luisa Roldán. Véase R. FERNÁNDEZ GRACIA, Op. cit., pp. 212-216, reproducidas en pp. 214 y 217, respectivamente.

${ }^{19}$ M. ESTELLA MARCOS, "La escultura napolitana...", pp. 100 y 103-104; e ÍDEM, “Caracteres del envío...", pp. 562-566. Se conservan otras obras firmadas de este mismo escultor en nuestro país como las localizadas en la catedral de Cuenca (J. NICOLAU CASTRO, "Esculturas napolitanas en la catedral de Cuenca", Boletín del Museo Nacional de Escultura, 6, Valladolid, 2002, pp. 36-38).

${ }^{20}$ Sobre la producción artística de Colombo en España véase R. ALONSO MORAL, "La scultura lignea napoletana in Spagna nell'età del barocco: presenza e influsso", en R. CASCIARO y A. CASSIANO (eds.), Sculture di età barocca tra Terra d'Otranto, Napoli e Spagna. Catálogo de la Exposición, Roma, 2007, pp. 79-86; e I. di LIDDO, Op. cit., pp. 180-214. ralar $^{21}$, Gonzalo M. Borrás y Germán López indican que estas cuatro imágenes habrían llegado a la capital del Jalón desde Roma y añaden que procederían de la desaparecida iglesia de Santiago ${ }^{22}$. No tenemos datos para negar que estas piezas llegaran a Calatayud desde la Ciudad Eterna, pero no dudamos de que previamente habían sido adquiridas en Nápoles.

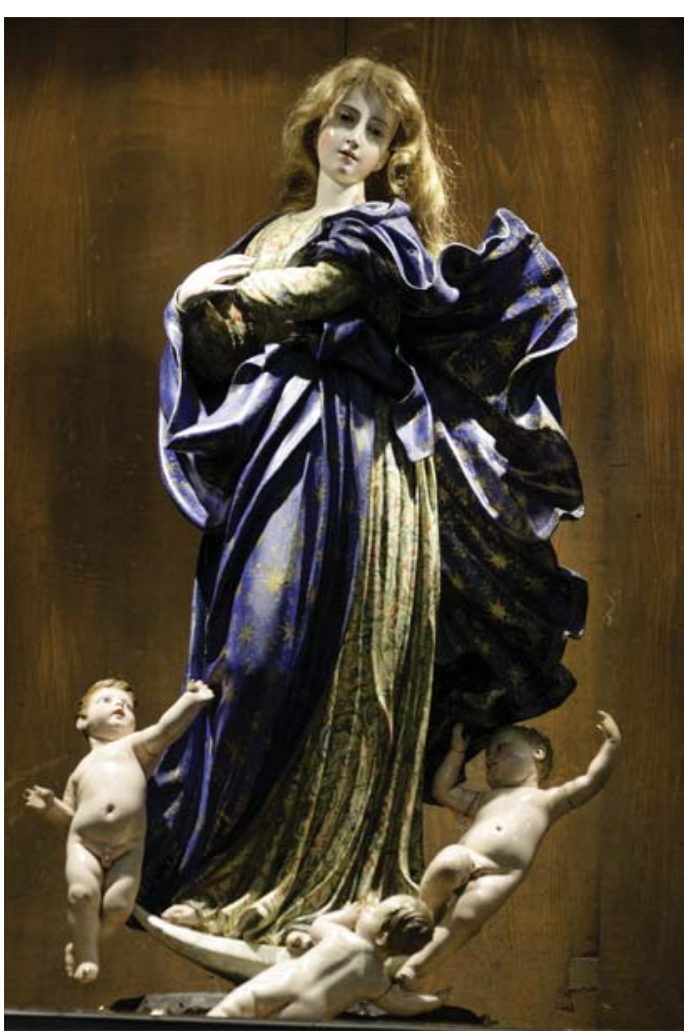

- Fig. 2. Inmaculada Concepción. Pietro Ceraso (atribuida). Colegiata del Santo Sepulcro de Calatayud. Foto Rafael Lapuente.

${ }^{21}$ M. del COS y F. EYARALAR, Glorias de Calatayud y su antiguo partido, Calatayud, 1845, ed. facsímil, 1988, p. 25.

${ }^{22}$ G. M. BORRÁS GUALIS y G. LÓPEZ SAMPEDRO, Guía Monumental y Artística de Calatayud, Madrid, 1975, p. 115. Sendas afirmaciones se siguen en E. QUINTANILLA y W. RINCÓN, “36. Inmaculada Concepción", en W. RINCÓN y E. QUINTANILLA (coords.), Mater Purissima. La Inmaculada Concepción en el arte de la diócesis de Tarazona, Zaragoza, 2005, pp. 180181; y en E. QUINTANILLA y W. RINCÓN, La Real Colegiata del Santo Sepulcro de Calatayud, Zaragoza, 2008, pp. 88-89. 
La talla de la Inmaculada Concepción, atribuida a Pietro Ceraso por la Dra. Estella Marcos, como ya avanzamos, se acomoda sobre una peana dorada con volutas y hojas de acanto acompañada de tres putti en actitud dinámica. La Virgen va ataviada con un manto azul ultramar decorado con estrellas doradas muy amplio y movido que incluso vuela tras su espalda y una túnica clara con motivos florales realizados a punta de pincel. En su rostro, de belleza idealizada, destaca su dulce y serena mirada a la que contribuyen eficazmente sus ojos de cristal. También su pelo, de color cobrizo, es postizo, rasgo habitual en las esculturas de Ceraso ${ }^{23}$. Ambos elementos ayudan a que las esculturas alcancen un mayor grado de naturalismo ${ }^{24}$.

Por su parte, consideramos que la excepcional imagen de San José con el Niño de la colegiata del Santo Sepulcro de Calatayud (Fig. 3) debe ponerse en relación con el círculo del escultor napolitano Gaetano Patalano y emparentarla con la talla de San Cayetano de Thiene de la iglesia de Santa Clara de Lecce firmada y fechada por dicho artífice en $1692^{25}$. San José aparece en pie sobre una peana de similares características a la de la Inmaculada Concepción de este mismo templo, y viste túnica y manto muy plegados, policromados en tonos marrones y pardos. Con su brazo derecho sujeta a su Hijo, que, dinámico y rollizo, intenta acariciarle la barbilla. Como la anterior, es de origen napolitano y ambas deben ser datadas en la última década del siglo XVII ${ }^{26}$.

${ }^{23}$ M. SÁEZ GONZÁLEZ, Del Reino de Nápoles a las Clarisas de Monforte de Lemos. Escultura del siglo XVII en madera, Lugo, 2012, p. 139. Deseamos mostrar nuestro agradecimiento al profesor Aurelio Á. Barrón por darnos a conocer esta referencia bibliográfica, así como por sus enriquecedoras observaciones sobre nuestro trabajo.

${ }^{24}$ R. CARRETERO CALVO, "Inmaculada Concepción”, en A. REINA DE LA TORRE y J. V. SANZ LOZANO (coords.), Symbolon. Brea de Aragón 2013. Catálogo de la Exposición, Zaragoza, 2013, pp. 152-153.

25 B. MINERVA, “39. San Gaetano Thiene”, en R. CASCIARO y A. CASSIANO (eds.), Op. cit., pp. 242243. Reproducida en p. 243.

${ }^{26}$ R. CARRETERO CALVO, "San José con el Niño", en A. REINA DE LA TORRE y J. V. SANZ LOZANO

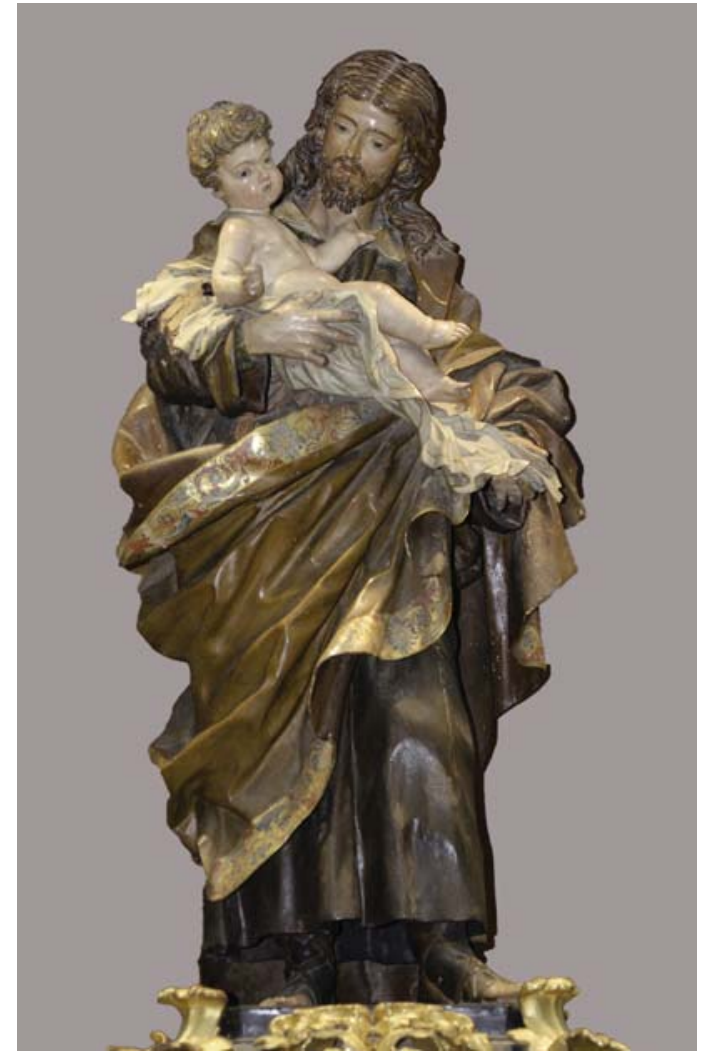

- Fig. 3. San José con el Niño. Gaetano Patalano (atribuido). Colegiata del Santo Sepulcro de Calatayud. Foto Rafael Lapuente.

En cambio, las exquisitas tallas de San Miguel y de San Jorge (Figs. 4 y 5) de esta misma colegiata están firmadas por el napolitano Jacobo Bonavita y fechadas en 1694 (Fig. 6) ${ }^{27}$, aunque tipológicamente parecen cercanas -sobre todo en el caso de la figura del soldado celestial- a la producción de Nicola $\mathrm{Fumo}^{28}$. Bonavita, uno de los mejores escultores del virreinato, cuenta con otra sober-

(coords.), Op. cit., pp. 166-167. En este estudio fechamos estas esculturas en la década de 1680, cronología que ahora retrasamos en unos diez años.

${ }^{27}$ Junto a la cabeza del demonio en la escultura del arcángel y bajo la pata trasera derecha del caballo en el caso de San Jorge. Deseamos mostrar nuestro agradecimiento a Miguel González, párroco-prior de la colegiata del Santo Sepulcro de Calatayud, por las facilidades prestadas para el estudio de estas piezas.

${ }^{28}$ Véase R. CASCIARO, “55. San Michele Arcangelo che abbate il Demonio", en R. CASCIARO y A. CASSIANO (eds.), Op. cit., pp. 274-275. Acerca de otros ejemplares de esta misma temática atribuidos igualmente a 
bia obra firmada y fechada en nuestro país: el Cristo de la Agonía de Urbasa (1703), en la actualidad en el Museo de Navarra, encargado por los Ramírez de Baquedano, marqueses de Andía, tal y como ha estudiado el profesor Fernández Gracia ${ }^{29}$. Este escultor, a quien cita Bernardo de Dominici en su obra Vite de' pittori, scultori ed architetti napoletani publicada entre 1742 y 1744, podría haber sido hijo de un artista homónimo fallecido en $1656^{30}$.

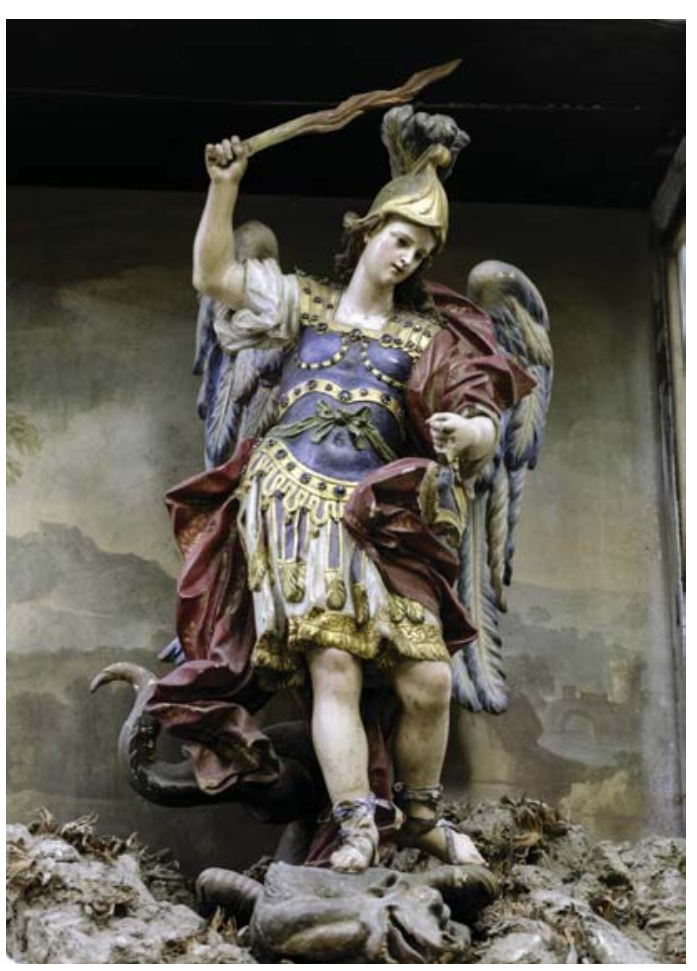

- Fig. 4. San Miguel venciendo al mal. Jacobo Bonavita, 1694. Colegiata del Santo Sepulcro de Calatayud. Foto Rafael Lapuente.

Fumo en nuestro país, véase M. ESTELLA MARCOS, “Caracteres del envío...", pp. 561-567.

${ }^{29}$ R. FERNÁNDEZ GRACIA, "Algunas esculturas napolitanas en Navarra", en ÍDEM (coord.), Pvlchrvm. Scripta varia in honorem $M^{a}$ Concepción García Gainza, Pamplona, 2011, pp. 304-307.

${ }^{30}$ Tanto el Cristo de Pamplona como el San Jorge y San Miguel de Calatayud, las tres firmadas y fechadas, imposibilitan que este escultor sea identificado con el Jacobo Bonavita fallecido en 1656. Véase B. DE DOMINICI, Vite de' pittori, scultori ed architetti napoletani, edición anotada a cargo de F. SRICCHIA e A. ZEZZA, vol. III, Nápoles, 2008, p. 729, nota no 10.

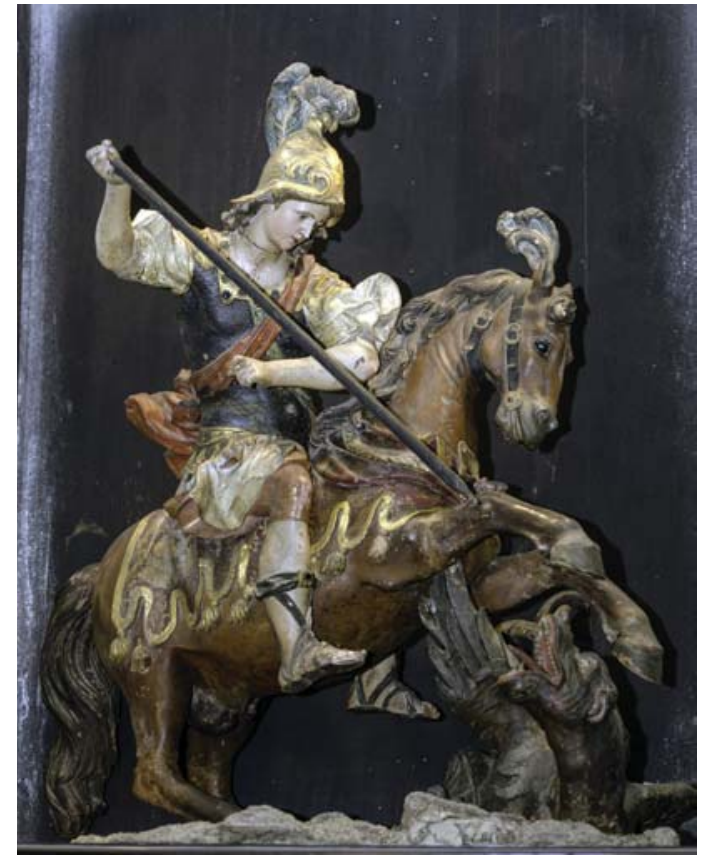

- Fig. 5. San Jorge y el dragón. Jacobo Bonavita, 1694. Colegiata del Santo Sepulcro de Calatayud. Foto Rafael Lapuente.

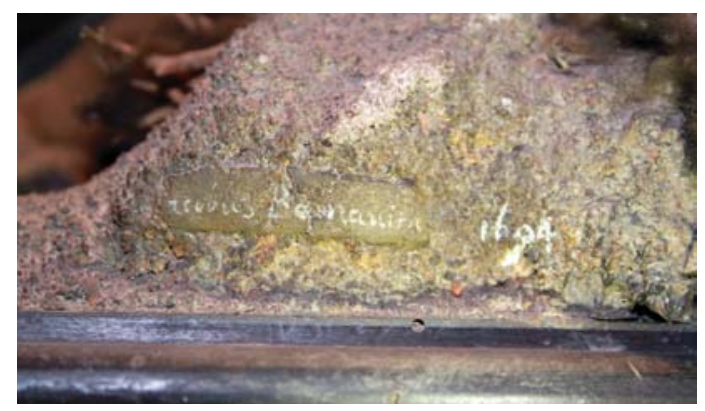

- Fig. 6. Detalle de la firma de Jacobo Bonavita. San Miguel venciendo al mal. Jacobo Bonavita, 1694. Colegiata del Santo Sepulcro de Calatayud. Foto de la autora.

En la sacristía mayor de la iglesia colegial de Santa María de la misma ciudad de Calatayud, instalada bajo un vistoso dosel rococó, se custodia otra escultura de la Inmaculada Concepción (Fig. 7), de modelo iconográfico distinto a las atribuidas a Pietro Ceraso. Tampoco dudamos en este caso de que se trata de una imagen napolitana, pese a que dicho extremo no se haya advertido en las dos ocasiones en que ha sido referencia- 


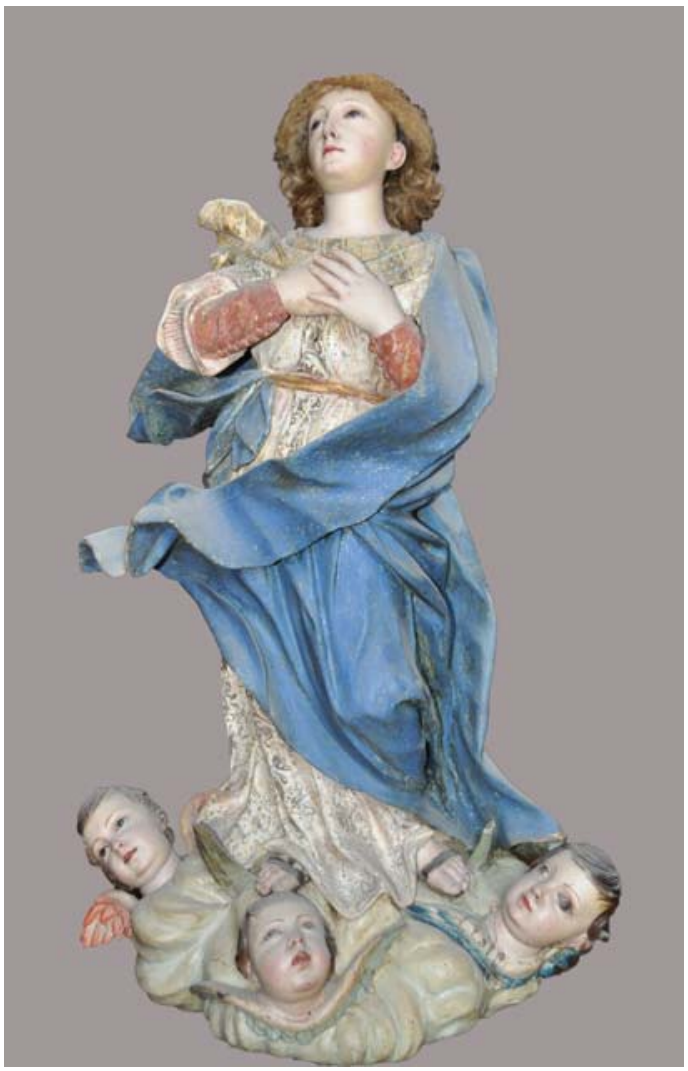

- Fig. 7. Inmaculada Concepción. Colegiata de Santa María de Calatayud. Foto Jesús Criado.

da en la bibliografía bilbilitana ${ }^{31}$. El tipo de esta Virgen Inmaculada es muy similar al de la talla de idéntica advocación del Museo de Bellas Artes de Bilbao firmada por Giacomo Colombo (1663-1731) y fechada hacia 1719 [no de inventario 82/401] $]^{32}$. El marcado contraposto de ambas esculturas, el manto azul que vuela hacia la derecha de María cruzando sus piernas, la peana decorada con tres querubines y la elevación y giro de sus cabezas hacia su derecha son rasgos que las aproximan $^{33}$. Sin embargo, la de Bilbao pare-

${ }^{31}$ G. M. BORRÁS GUALIS y G. LÓPEZ SAMPEDRO, Op. cit., p. 66; y E. QUINTANILLA y W. RINCÓN, "40. Inmaculada Concepción", en W. RINCÓN y E. QUINTANILLA (coords.), Op.cit., pp. 188-189.

${ }^{32}$ R. ALONSO MORAL, Op. cit., pp. 163-193, reproducida en p. 167.

${ }^{33}$ Este modelo iconográfico lo encontramos asimismo en la bella Inmaculada Concepción del retablo de la capilla de la Virgen del Camino de la iglesia de San Cernin de Pamplona remitida en 1772, junto a una imagen ce querer juntar las manos por delante de su pecho, mientras que la bilbilitana las cruza a la altura del corazón. Hemos de reconocer que la calidad artística de la pieza de Calatayud es manifiestamente inferior que la firmada por Colombo, a lo que contribuye el cabello postizo y los desmedidos ojos de cristal de la primera, razón por la que cabe pensar que, en todo caso, se trataría de una obra de taller.

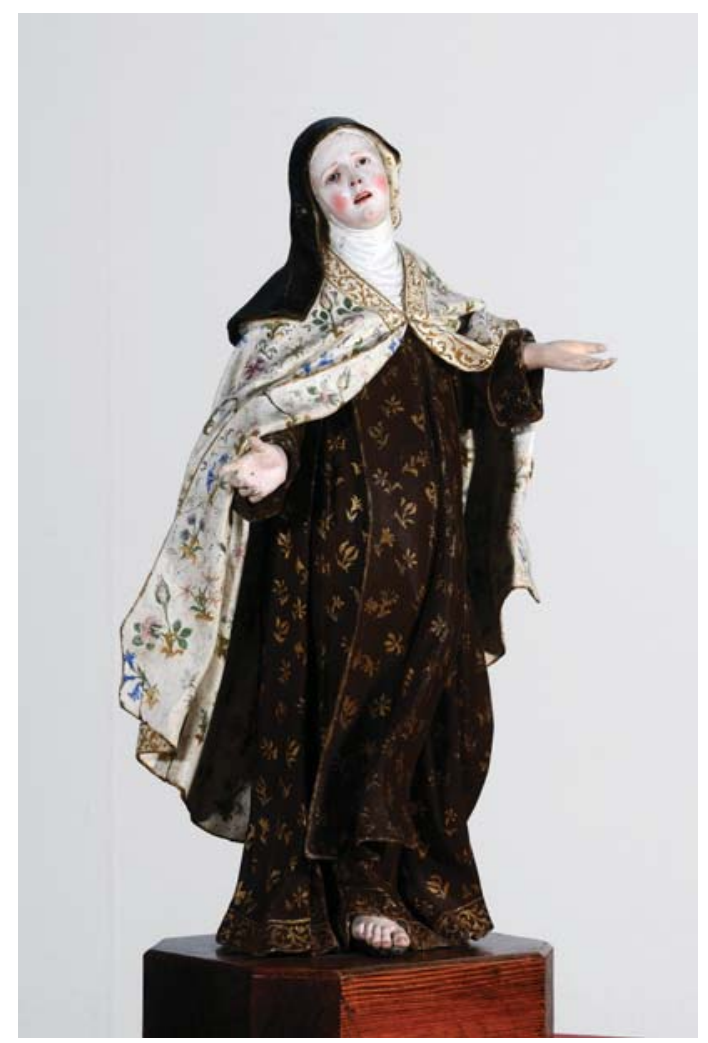

- Fig. 8. Santa Teresa de Jesús. Gaetano Patalano (atribuido). Diputación Provincial de Zaragoza. Archivo DPZ Foto Daniel Pérez 2012.

Por último, también parece proceder de Calatayud, concretamente del Hospicio Provincial de la ciudad, una delicada talla de Santa Teresa de Jesús perteneciente a la Diputación de Zaragoza $^{34}$ (Fig. 8) que podría

de Santa Teresa de Jesús, por Agustín de Leiza y Eraso, residente en la Corte y miembro del Consejo y Cámara de Su Majestad. R. FERNÁNDEZ GRACIA, "Algunas esculturas...", pp. 308-309.

${ }^{34}$ R. CARRETERO CALVO, "Estudio histórico-artístico de la Escultura de Santa Teresa de Jesús de la Di- 
adjudicarse al círculo del escultor Gaetano Patalano por su proximidad a la Santa Escolástica que dicho artífice llevó a cabo para la iglesia de San Juan Evangelista de Lecce $(1692)^{35}$. Nos encontramos ante una deliciosa escultura de la Santa abulense ataviada con el hábito del Carmelo descalzo, Orden que ella misma fundó en 1562. Éste se compone de velo negro, toca y manto de color blanco, hábito y escapulario marrones oscuros, aunque en esta ocasión aparecen decorados con ricos motivos vegetales y florales realizados a punta de pincel, y sandalias.

Teresa, de cuerpo entero, ha sido dotada de un bello e idealizado rostro en el que, entre sus pequeñas facciones, destacan sus ojos de cristal y el hoyuelo de su barbilla, rasgos que se aproximan poco a la vera effigies que fray Juan de la Miseria pintó de ella en 1576 y que se conserva en el convento de San José de Sevilla. Su arrobado gesto, unido a la movida posición de los plegados de la zona inferior del escapulario, así como del velo y del hábito, le otorgan un dinamismo $y$ un efecto de teatralidad excesivos que nos inducen a pensar que la iconografía no está completa. A esto debemos añadir que en el centro de las palmas de sus manos aparecen sendas pequeñas perforaciones probablemente causadas por la inserción de algún atributo que no ha llegado a nuestros días. Aparte de esto, la forma en la que el velo se recoge voladamente hacia atrás da la sensación de que sobre su hombro derecho se disponía otro elemento.

La imagen bilbilitana es especialmente próxima a la figura de la abulense, de gusto rococó, del retablo de la Virgen del Camino de la iglesia de San Cernin de Pamplona. Dicha escultura, junto con la de la Inmaculada Concepción de este mismo mueble, fue enviada por el aragonés Agustín de Leiza y

putación de Zaragoza", en J. I. CALVO RUATA (coord.), Joyas de un patrimonio IV. Catálogo de la Exposición, Zaragoza, 2012, pp. 383-385.

${ }^{35}$ Reproducida en R. CASCIARO, "43. Santa Scolastica", en R. CASCIARO y A. CASSIANO (eds.), Op. cit., p. 251.
Eraso en marzo de 1772 al templo pamplonés, especificándose que se trataba de "dos bultos especiales de echura de Napoles"36. También en Navarra, en la sacristía mayor de la catedral de Tudela se conserva otra escultura de origen napolitano de Santa Teresa de Jesús, en esta ocasión representada como escritora, junto a una de San José, donativo de Sebastián Cortés y Lacárcel, que fue deán de este templo entre 1693 y $1703^{37}$, es decir, cuando todavía esta localidad se integraba en la diócesis de Tarazona.

En la escultura bilbilitana, como en la de Pamplona, Teresa aparece en contraposto, en actitud arrebatada y vestida con el hábito carmelitano ricamente ornado con florecillas. Sin embargo, la de Pamplona está acompañada de un pequeño ángel portador de una larga flecha que le atraviesa el corazón. En ésta se ilustra, pues, un episodio de su biografía acaecido hacia 1562, su más famoso éxtasis conocido como la Transverberación, que ella misma relata en el Libro de la vida. Todo ello nos hace pensar que la hipótesis más probable es que la escultura que nos ocupa también representase la Transverberación y que entre los elementos hoy perdidos se encuentren el dardo y el ángel.

PIEZAS NAPOLITANAS EN EL CONVENTO DE LA INMACULADA Y SAN BLAS DE MIEDES

Como ya hemos advertido, en el coro alto de la clausura de las concepcionistas de la Inmaculada y San Blas de Miedes de Ara-

${ }^{36}$ R. FERNÁNDEZ GRACIA, El retablo barroco en Navarra, Pamplona, 2002, pp. 397-400; e ÍDEM, La Inmaculada Concepción en Navarra. Arte y devoción durante los siglos del Barroco. Mentores, artistas e iconografía, Pamplona, 2004, pp. 134-137.

${ }^{37}$ R. FERNÁNDEZ GRACIA, "Santa Teresa y San José", en Má I. FABAR SARRÍAS, J. SESMA SESMA, J. SANCHO DOMINGO y M. JOVER HERNANDO (comis.), Tudela. El legado de una catedral. Catálogo de la Exposición, Pamplona, 2006, pp. 229-230; ÍDEM, "Patronos, proyectos y artistas durante los siglos del barroco", en AA.VV., La catedral de Tudela, Pamplona, 2006, p. 294 e ÍDEM, "Algunas esculturas...", pp. 300-310, reproducidas en pp. 307-308. 
gón se conserva una pieza de composición y procedencia similar a la Virgen Inmaculada del Santo Sepulcro de Calatayud, así como de policromía prácticamente idéntica (Fig. 9) -aunque de menor calidad artística-, que ha sido atribuida a Pietro Ceraso ${ }^{38}$. No obstante, existen algunas diferencias entre ambas esculturas que otorgan mayor prestancia, si cabe, a la bilbilitana. En primer lugar, tres angelotes de cuerpo entero que incluso invaden la peana acompañan a la talla de María del Santo Sepulcro, mientras que son tres grandes cabezas de querubines las que ornan las nubes sobre las que se acomoda la Virgen de Miedes. Además, la Inmaculada del Santo Sepulcro recoge sus manos sobre el pecho mientras que la de Miedes las junta por delante en señal de oración.

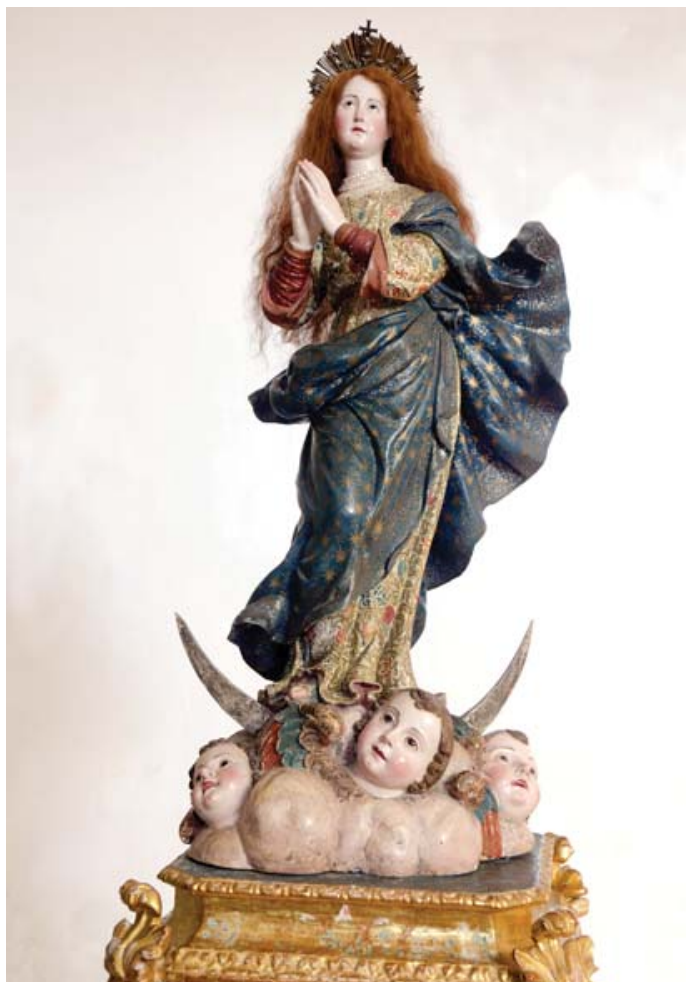

- Fig. 9. Inmaculada Concepción. Pietro Ceraso (atribuida). Convento de concepcionistas de Miedes. Foto Rafael Lapuente.

Esta imagen se encontraba ya en el cenobio cuando la madre Ana María Teresa de

${ }^{38}$ M. ESTELLA MARCOS, "La corte virreinal...", pp. 231-232.
Jesús y Langa (1649-1733) encargó, gracias al dinero que le enviaban su madre y parientes, la confección de una caja de madera dorada para albergarla en cuyo fondo se incluyen las letanías marianas pintadas ${ }^{39}$.

Las concepcionistas atesoran asimismo la talla del Niño Jesús ya mencionada al tratar del grupo escultórico de San José con el Niño del cenobio de Ágreda. Se trata de un Niño Jesús vestido de Nazareno, inédito hasta este momento y que, con el rostro afligido, parece reflexionar ante la cruz que porta en su mano izquierda (Fig. 1). Consideramos esta imagen próxima a la obra de Patalano pues encontramos concomitancias entre éste y, por ejemplo, el putto que acompaña a la Santa Escolástica de la iglesia de San Juan Evangelista de Lecce datado hacia 1692 y adjudicado a Patalano no hace demasiados años ${ }^{40}$.

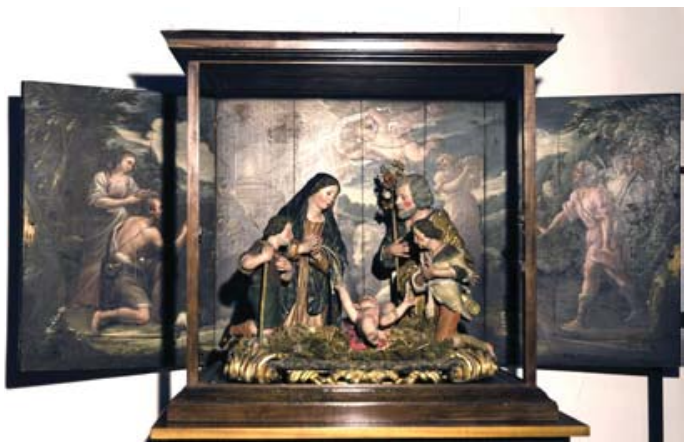

- Fig. 10. Belén napolitano en su caja. Convento de concepcionistas de Miedes. Foto Rafael Lapuente.

Las religiosas de Miedes también custodian un precioso Belén napolitano incluido en una caja pintada con la representación del buey, el ángel, la paloma sím-

${ }^{39}$ Así se narra en Fr. C. LANGA, Vida, y virtudes de la Venerable Madre Ana María Teresa de Jesús y Langa, Zaragoza, 1739 , p. 40. Deseamos mostrar nuestro agradecimiento a la comunidad de religiosas de Miedes por su disposición para el estudio de estas piezas, así como a José Luis Cortés Perruca por sus infalibles gestiones para que pudiéramos acceder a la clausura.

${ }^{40}$ R. CASCIARO, "43. Santa Scolastica", en R. CASCIARO y A. CASSIANO (eds.), Op.cit., pp. 250-251 e I. di LIDDO, Op. cit., p. 127. Reproducida en p. 125. 
bolo del Espíritu Santo y pastores con sus rebaños cuyos paneles se abren (Fig. 10) ${ }^{41}$. Consta de cinco tallas -la Virgen, San José, el Niño y dos pastores que adoran al recién nacido- y su factura debemos relacionarla con la Inmaculada Concepción de este mismo cenobio.

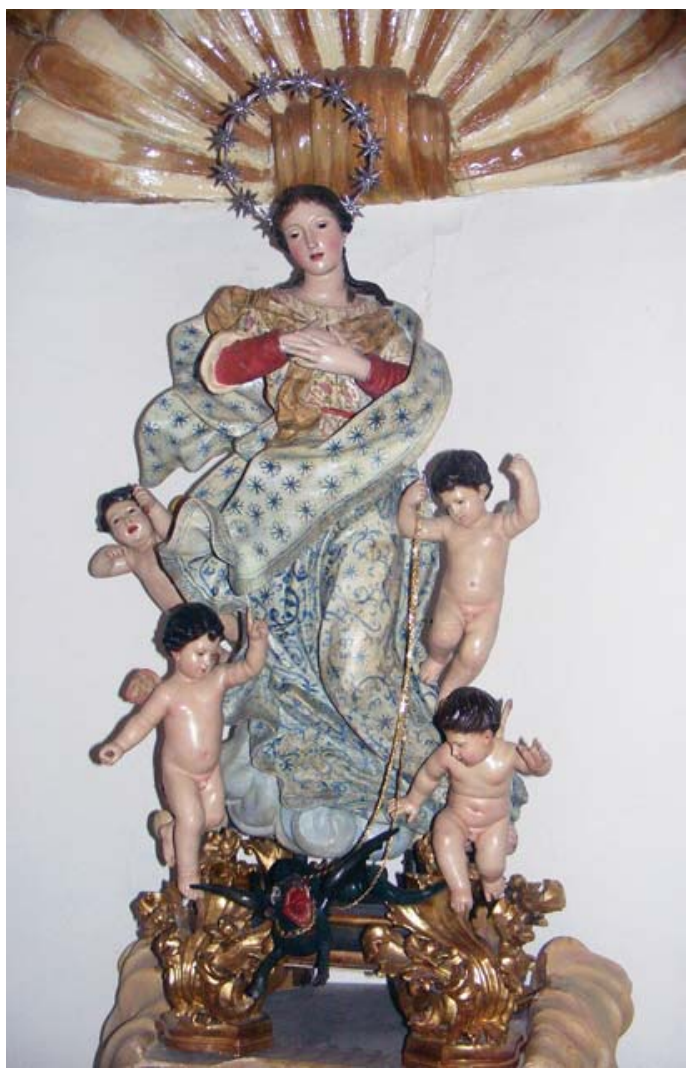

- Fig. 11. Inmaculada Concepción conocida como «La Napolitana». Gaetano Patalano (atribuida). Convento de la Concepción de Borja. Foto Alberto Aguilera.

\section{LAS DOS «NAPOLITANAS»DE BORJA}

La localidad de Borja (Zaragoza) atesora otras dos muestras de escultura napolitana con la representación de la Virgen Inmaculada. Según cuenta la tradición oral del convento de Santa Clara de Borja, un matrimonio infanzón acudió al cenobio con dos esculturas de la Inmaculada Concepción. Pese a que parece que las clarisas eli-

\footnotetext{
${ }^{41}$ Agradecemos su conocimiento a la generosidad
} de José Luis Cortés Perruca. gieron en primer lugar no tomaron la talla de mayor calidad artística, mientras que el otro convento femenino borjano, de concepcionistas, se llevó la mejor parte ${ }^{42}$. Efectivamente, la imagen de María, de extraordinaria belleza, se conserva en el convento de la Concepción y es conocida como «La Napolitana» (Fig. 11) $)^{43}$.

El movimiento de su vestimenta, el dinamismo de los angelotes que la acompañan y el alargamiento de su rostro evocan la obra de Gaetano Patalano y, en concreto, recuerdan la efigie de María del relieve de la Coronación de la Virgen de la catedral de Cádiz -firmado por Patalano en 1694-44, la Madonna del Carro fechada en 1699 y custodiada en el Museo Provinciale «Sigismondo Castromediano» de Lecce ${ }^{45}$, o incluso la Immacolata (1692) de la iglesia de Santa Clara ${ }^{46}$

\footnotetext{
${ }^{42}$ Agradecemos esta información al investigador Alberto Aguilera Hernández, director del Museo de Santa Clara de Borja.

${ }^{43}$ B. BOLOQUI LARRAYA, "Inmaculada Concepción", en M. C. LACARRA DUCAY y F. VILLAR PÉREZ (coords.), María en el arte de la ciudad de Borja. Guía para una exposición, Borja, 1989, pp. 23-25; y E. QUINTANILLA y W. RINCÓN, "35. Inmaculada Concepción”, en W. RINCÓN y E. QUINTANILLA (coords.), Op. cit., pp. 178-179. El proceso de restauración de la pieza se destaca en P. FERRER CÓRDOBA, "Restaurada la bella imagen de «La Napolitana» del convento de la Concepción de Borja", Boletín Informativo del CESBOR, 109-110, 2005, p. 12.

${ }^{44}$ A. di LUSTRO, Gli scultori Gaetano e Pietro Patalano tra Napoli e Cadice, Nápoles, 1993. Reproducida en R. CASCIARO, "Napoli vista da fuori: sculture di età barocca in Terra d'Otranto e oltre", en R. CASCIARO y A. CASSIANO (eds.), Op. cit., p. 61.

${ }^{45}$ Esta escultura ha sido tradicionalmente atribuida a Nicola Fumo (véase L. GAETA, "57. Madonna del Carro", en R. CASCIARO y A. CASSIANO (eds.), Op. cit., pp. 280-281), aunque hoy en día se adjudica a Gaetano Patalano (en I. di LIDDO, Op. cit., pp. 131-136). De hecho, como expresa Francesco Abbate, la filiación entre Fumo y Gaetano Patalano es realmente estrecha (F. ABBATE, Storia dell'arte nell'Italia meridionale, IV, Il secolo d'oro, Roma, 2002, p. 156). Pieza reproducida en L. GAETA, “57. Madonna del Carro", en R. CASCIARO y A. CASSIANO (eds.), Op. cit., p. 281.
}

${ }^{46}$ B. MINERVA, "37. Immacolata", en R. CASCIARO y A. CASSIANO (eds.), Op. cit., pp. 238-239. Una 
de la misma población ${ }^{47}$. De igual modo, debemos advertir que la Virgen borjana guarda una estrecha similitud con la Inmaculada con hidra de las siete cabezas de la clausura de las clarisas de Monforte de Lemos (Lugo), atribuida recientemente a Gaetano Patalano ${ }^{48}$.

Por su parte, inferior categoría y mínima belleza presenta la segunda Inmaculada borjana también conocida por sus propietarias, las clarisas, como «La Napolitana»" ${ }^{49}$ Su ubicación original la situaba en la hornacina central del coro bajo flanqueada por Santa Clara y San Francisco. Sin embargo, con la transformación en capilla de dicho espacio, la talla pasó a ocupar una de las laterales puesto que en la central se colocó el sagrario $^{50}$. Pese a sus carencias artísticas y a los repintes que muestra, no descartamos su proximidad a las obras anteriores a la plenitud de Giacomo Colombo (1663-1731), en concreto a la Inmaculada Concepción de la iglesia de San Francesco de Éboli, fechada hacia $1700^{51}$.

\section{ESCULTURAS PROCEDENTES DE NÁPOLES EN LA ERMITA DE SANTA ANA DE CARENAS}

En la ermita de Santa Ana de Carenas (Zaragoza), población perteneciente al antiguo arcedianado de Calatayud, se cobijan dos extraordinarias esculturas sobre sendas peanas rococó cuya procedencia nos parece asimismo napolitana. La primera de ellas representa a San Onofre (Fig. 12), mientras que

buena reproducción de esta escultura se encuentra en I. di LIDDO, Op. cit., p. 133.

${ }^{47}$ Sobre estas obras véase I. di LIDDO, Op. cit., pp. 94-141.

${ }^{48}$ M. SÁEZ GONZÁLEZ, Op. cit., pp. 136-137, reproducida en $\mathrm{p} .136$.

${ }^{49}$ La imagen de esta escultura puede encontrarse en el blog del Centro de Estudios Borjanos de la Institución «Fernando el Católico», consultado el 22 de diciembre de 2013. URL: http://cesbor.blogspot.com.es/2012/12/ en-la-fiesta-de-la-inmaculada-concepcion.html

${ }^{50}$ Debemos estos datos a Alberto Aguilera.

${ }^{51}$ R. ALONSO MORAL, “La Inmaculada...", p. 179, reproducida en p. 181 (Fig. 11).

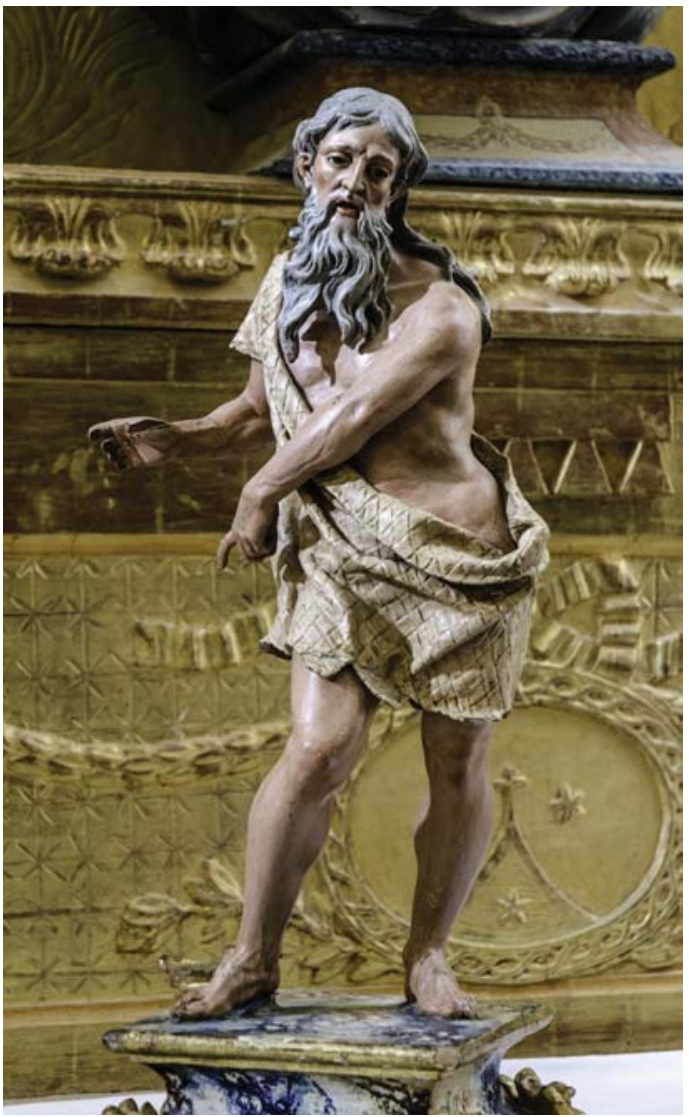

- Fig. 12. San Onofre. Círculo de Giacomo Colombo (atribuido). Ermita de Santa Ana de Carenas. Foto Rafael Lapuente.

la segunda encarna a San Juan Bautista. Esta última aparece desprovista de la figura del cordero a la que señala con la mano derecha, así como de la caña que sostendría con la izquierda (Fig. 13). Nos encontramos ante dos imágenes desconocidas hasta este momento que fueron realizadas por el mismo escultor ${ }^{52}$. El marcado contraposto, la ondulación casi serpentina de sus cuerpos, su fornida anatomía y el tratamiento del cabello en guedejas nos aproximan a la producción artística de Giacomo Colombo ${ }^{53}$, por ejemplo al soberbio Cristo atado a la columna firmado y fechado en 1698 conservado actualmente en la catedral

\footnotetext{
${ }^{52}$ Agradecemos encarecidamente a José Luis Cortés Perruca el conocimiento de estas bellísimas tallas.

${ }^{53}$ Además de la bibliografía ya citada sobre Colombo, puede consultarse L. GAETA, "Giacomo Colombo tra compari, amici e rivali", en R. CASCIARO y A. CASSIANO (eds.), Op. cit., pp. 87-104.
} 
de la Almudena de Madrid para el caso del San Juan Bautista de Carenas, así como al no menos extraordinario San Andrés (1706) de la iglesia parroquial de la misma advocación de Gricignano di Aversa, para el San Onofre.

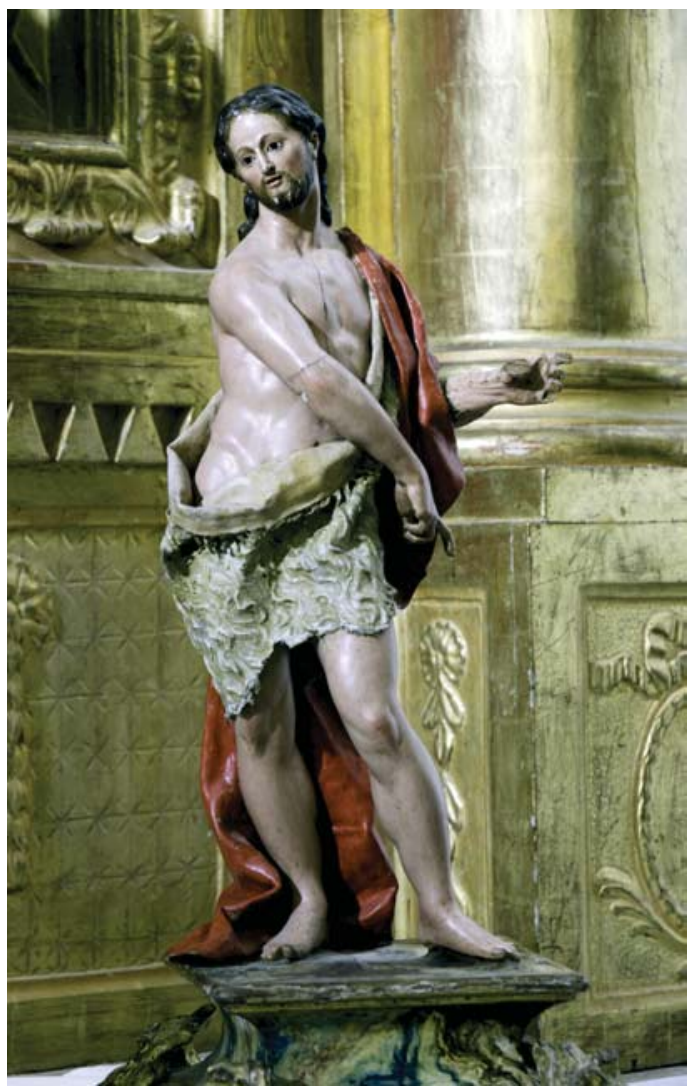

- Fig. 13. San Juan Bautista. Círculo de Giacomo Colombo (atribuido). Ermita de Santa Ana de Carenas. Foto Rafael Lapuente.

\section{CONCLUSIONES}

A lo largo de estas páginas hemos reunido numerosos y heterogéneos ejemplos de escultura napolitana cuyo punto de uni- dad se encuentra en que todas ellas se atesoran en la diócesis de Tarazona. La primera conclusión a la que podemos llegar es que algunas de estas piezas, conocidas o inéditas hasta el momento, presentan una elevada calidad artística. Sin embargo, hemos de lamentar que sólo en las tallas custodiadas en el convento de concepcionistas descalzas de Ágreda conocemos la identidad del comitente certificando que en todos los casos se trata de personajes vinculados con el virreinato de Nápoles o de la alta aristocracia hispánica. Para el resto de los ejemplos, la ausencia de documentación y de estudios e investigaciones de los monumentos que los albergan nos impiden, hasta el momento, ir más allá de la mera intuición de que sus mecenas fueron asimismo prohombres y con más probabilidad eclesiásticos, como vimos al citar el caso documentado del colegio jesuítico de Tarazona, relacionados por diferentes causas con las distintas poblaciones mencionadas.

Asimismo, en esta primera aproximación al tema hemos intentado adjudicar la factura de la mayoría de las tallas italianas que presentamos a sus correspondientes autores o, en su defecto, a su círculo, aunque siempre con la prevención ya señalada de que la semejanza y la conexión de gran parte de los escultores del ámbito napolitano, a lo que debemos de sumar la ausencia de firmas -con la excepción de las magníficas obras rubricadas por Bonavita custodiadas en Calatayud-y de documentación de las piezas estudiadas, dificultan el cierre definitivo de estas atribuciones artísticas. 